Research Article

\title{
Serious games as social innovation tools
}

Marion Litaiff Azize Gomes ${ }^{{ }^{*}}$ (D); Célia Maria da Silva Carvalho ${ }^{1}$ (D); Augusto César Barreto Rocha ${ }^{1}$ (D)

${ }^{1}$ Programa de Pós-graduação em Design, Faculdade de Tecnologia, Universidade Federal do Amazonas - UFAM, Manaus, Amazonas, Brasil

\begin{abstract}
:
Serious games are games with specific purposes that go beyond entertainment and are utilized for a wide range of purposes. This article sought to investigate whether serious games can conceptually be considered as social innovation tools and be used to achieve social innovation goals based on studies surrounding both subjects. A two-phase research was carried out, the first being a literature review of qualitative nature of publications that characterized the subjects around serious games and social innovation, and the second being an investigation of four existing serious games to evaluate whether the link between both subjects could be found in real cases. The study allowed the creation of a table identifying in the serious games different social innovation reoccurring themes gathered in the first phase of the research. The results also suggest that the concepts and objectives of serious games and social innovation have many correlations, such as both being considered creative strategies to present solutions to minimize social problems, social innovation being a broader concept that encompasses different methods, and serious games being considered one of them. Therefore, it was concluded that serious games indeed can be considered tools for social innovation, answering the main question of the article.
\end{abstract}

Keywords: serious games, social innovation, social impact.

\section{Introduction}

The world population faces several social challenges daily, and the search for innovative solutions to alleviate them has been a topic of discussion in recent years. Even though the diagnoses of each of these problems are different, one of the concepts that emerged to alleviate them is social innovation. Social innovation is considered a way to respond to social problems by mobilizing creativity to develop solutions and make the best use of scarce resources to solve problems (Avelino et al., 2019). Innovation scholars approach social innovation conceptually as new social technologies that create social value (Van Der Have \& Rubalcaba, 2016), representing a response to a human problem or need or a shared value, the result of a collaboration between different actors, interpersonal activities, or social interactions to meet one or more common goals (Correia et al., 2018). Its field is based on the creation of solutions to social needs and is driven by agents who organize themselves under the most different legal types, being considered by managers as a new dimension for strategy and planning in organizations. (Andrade et al., 2021).

Another concept that has been presented to get to know and face social challenges are serious games, with specific purposes, which go beyond entertainment and have been used for a wide range of goals. They have at least four general characteristics that highlight their potential usefulness: universal language, flexibility to explore uncertainties and complexities, ability to facilitate learning, and the opportunity they provide for timely collection of relevant data (Olejniczak et al., 2020). Therefore, this article sought to investigate the use of serious games as a method to achieve social innovation goals.

\section{Research method}

This article sought to investigate whether serious games can conceptually be considered as social innovation tools and be used to achieve social innovation goals. For this purpose, this research was carried out in two phases. In the first phase a literature review of a qualitative nature was carried out by gathering and analyzing publications that characterized the subjects around serious games and social innovation, to possibly establish a conceptual link between the two areas. Peer-reviewed articles published in the last five years (2016-2021) were prioritized, aiming to investigate the most recent advances in studies on the subjects, to ascertain their concepts, their goals

Received: September 29, 2021. Accepted: November 24, 2021.

*Corresponding author: Marion Litaiff Azize Gomes. E-mail: marionlitaiff@ufam.edu.br

(cc) BY This is an Open Access article distributed under the terms of the Creative Commons Attribution License, which permits unrestricted use, distribution, and reproduction in any medium, provided the original work is properly cited. 
and how both themes can be related. The articles were found in different journals databases, utilizing keywords such as "serious games", "social innovation", "social change", "board game", and "digital game".

The second phase aimed to evaluate a possible link between the two subjects by analyzing real existing serious games. Therefore, it was decided to describe and evaluate four games: Good Shrimp Farming, Orbit Rescue, Bow River Sim and Rise Up. These games were chosen because they were developed and applied with the intention of solving or alleviating social problems, making it possible to compare its purposes with reoccurring themes of study of social innovation. It was also decided to analyze both analogue and digital games, to explore the topic in different media. The games were also found within scientific articles, and the focus was to identify its characteristics, origin, developers and, mainly, their main goal with the implementation of the game.

\section{Literature review}

\subsection{Use of games for social issues and serious games}

In 1949, the Dutch historian and linguist Johan Huizinga created the term Homo Ludens, stating that the game is something innate to man and even to animals, fitting into an absolutely primary category of life, even prior to culture, which evolved from the game. He also stated that, even in its simplest forms, the game is more than a physiological phenomenon or a psychological reflex, it goes beyond the limits of a purely physical activity (Huizinga, 2014). The author identifies the playful experience in the great archetypal activities of human society, such as in the case of the creation of language, because behind every abstract expression there is a metaphor, and every metaphor is a play on words.

In addition to their playful function, games offer a less threatening way to explore and explain complex issues to society. Johnson (2016) recalls that even common games have for many decades been used as metaphors to clarify more complex socioeconomic processes, exemplifying with the fact that, in the 13th century, the Dominican monk Jacobus de Cesolli used chess as a metaphor to explain significant changes in European governance, and his book on the subject was surpassed in popularity only by the Bible, in the 15th century (Johnson, 2016). Even though games are neither the first nor the only option for managing serious issues of civic participation, they open up new possibilities for engagement and contribute to the diversification of methods and tools available to the facilitators of these processes. Agents who plan solutions to complex issues recognize the value and benefits of games to help, trigger group discussions and illustrate and support decision-making processes (Ampatzidou et al., 2018). Rocha (2018) reports that games enable the exploration of imaginary spaces and the manipulation of symbolic systems, therefore, players form opinions when interacting with them, also forming critical thinking. The author states that games are expressive cultural artifacts, with the ability to persuade and create meaning, which can result in long-term social changes (Rocha, 2018).

More recent studies identify games as having more complex and specific goals. Medeiros (2019) explains that games are aligned with learning, as they encourage cooperation and favor immersion, bringing participants to a state of belonging to what is being addressed. Designers and brand managers, for example, are able to think of playful structures for different processes, as games can serve as a learning, simulation and participation tool, and, most importantly, make collaborative processes rich in ideas and possibilities (Medeiros, 2019). Research in this area offers an interdisciplinary picture that includes a variety of professions and suggests that games respond to the needs of government institutions, industry, and individuals (Klabbers, 2018).

When studying their application of games in public policy, Olejniczak et al. (2020) defined serious games as analogue or digital, used within a well-defined space and with a clear primary purpose, other than entertainment, intentionally projecting the gaming experience into reality. The purpose and method of transferring the information you wish to pass on are determined by the person or organization applying the game. Serious games present a promising method for capturing timely data about how people actually behave, not just how they claim. This measurement can be taken before, during and after the game (Olejniczak et al., 2020). The use of serious games presents motivations to encourage learning and can be especially useful to increase understanding, while its socialization aspect can contribute to inclusion.

Serious games currently represent a growing segment of the gaming market. By 2025, the serious gaming market will exceed 9.17 billion dollars in revenue, with an annual growth rate of 19.2\% (Allied Market Research, 2019). Although the leisure games market and industry provide the basis for the worldwide dissemination of game culture, genres, platforms, and tools available to develop them, it is the increasing development and use for special purposes and for serious use that provides an important contribution to social inclusion. They are increasingly being used as a general term to include use of games in education, training, health, wellness, advertising and communication and various fields of non-formal education (Stewart et al., 2013).

In reviewing how researchers reflect on the impact of serious games, Mayer et al. (2016) detected the presence of at least four main goals: 1) Serious games as a tool/therapy: used for a wide range of purposes, such as, for 
example, therapy, education, health, decision-making and training; 2) Serious games as creative innovation: considering that games are surrounded by technological innovation, creativity and other processes that generate competitive advantage in design, production and organization, they are seen as part of evolutionary change and as a significant factor in competition between nations, regions, companies and individuals; 3) Serious games as a form of persuasion: can be seen as a powerful new means of communication and an even more effective means of persuasion and rhetoric, which can be used to sell products or services, such as advergames and branding games, as well as to effect changes in social behavior, such as to prevent bullying. 4) Serious games as a form of self-organization: games can affect the ways in which people organize and interact in everyday life, whether in social, political, cultural, or at work, such as in organization from crowdsourcing to answer scientific questions (Mayer et al., 2016).

Drummond et al. (2017) explain that, in order to develop serious motivating games, it is necessary to find a point of balance where the users' intrinsic and extrinsic motivations can converge. To increase their learning effectiveness, serious games must be based on a framework derived from cognitive science called the four pillars of learning: attention, active learning, feedback, and consolidation, described in Table 1 (Drummond et al., 2017).

Table 1. The four pillars of learning to increase the effectiveness of serious games.

\begin{tabular}{|c|c|c|c|}
\hline Learning Pillars & Goals & $\begin{array}{c}\text { Implications for Serious Game } \\
\text { Development }\end{array}$ & $\begin{array}{c}\text { Implications for Implementing } \\
\text { Serious Games }\end{array}$ \\
\hline Attention & $\begin{array}{l}\text { To select relevant information. } \\
\text { To stay focused on the serious } \\
\text { game }\end{array}$ & $\begin{array}{l}\text { Promote strategies that help } \\
\text { select relevant information } \\
\text { (modeling, feedback, virtual } \\
\text { tools) }\end{array}$ & $\begin{array}{l}\text { Enforcers should discuss with } \\
\text { players at the end of the session } \\
\text { to ensure they have identified } \\
\text { relevant information }\end{array}$ \\
\hline Active learning & Being involved during learning & $\begin{array}{l}\text { Promote interactivity instead of } \\
\text { conveying content through text } \\
\text { or audio explanation }\end{array}$ & There is not \\
\hline Feedback & $\begin{array}{l}\text { To assess the gap between goal } \\
\text { and performance }\end{array}$ & $\begin{array}{l}\text { Promote the use of feedback that } \\
\text { addresses the task performed }\end{array}$ & $\begin{array}{l}\text { Applicants can report player } \\
\text { performance at the end of the } \\
\text { serious game session }\end{array}$ \\
\hline Consolidation & To achieve long term memory & $\begin{array}{l}\text { Promote repetition of } \\
\text { interactions with important in- } \\
\text { game learning content }\end{array}$ & $\begin{array}{l}\text { Promotes education with } \\
\text { multiple training sessions and } \\
\text { multiple educational methods }\end{array}$ \\
\hline
\end{tabular}

Source: Own elaboration based on Drummond et al. (2017).

Serious games are a practice used in different areas. Wilkinson (2016) claims that they have become a legitimate medium for education, health, and social change. The field of study has become increasingly interdisciplinary, starting with simple origins, in the convergence of computational modeling and non-digital game-based learning, now the field is a nexus for several other disciplines. The research and practices of serious games are beginning to shape the practices of the contexts in which they are used (Wilkinson, 2016). In addition to it's use for learning and education, there has been increasing deliberation about the effectiveness of serious games for social change and other serious purposes. There are games that support learning from civics to physics, from empathy skills to math facts. Serious games are being used to teach surgical procedures, to raise awareness about global issues such as domestic violence and oppression, and to practice speaking with war veterans suffering from post-traumatic stress (Schrier, 2016).

Through a literary review regarding business games and creativity, Rosa et al. (2019) came to the conclusion that serious games show great results and tend have a positive performance in people's learning capacity, stimulating social and cognitive characteristics, because weather if it's individually or in a group, the process to achieve the goals of the game allow immersion and engagement, and the participants exercise different skills, such as decision-making, communication and creativity. It is important, therefore, to focus on the objective of 
the game, with how the players will interact and what is the result expected from the experience, as the type of game chosen must match the moderates' objectives (Rosa et al., 2019).

Serious games provide a way for interested parties to engage and understand the issues and constraints in a real-world system, but to do so requires an aspect of game play, simulation and learning in almost equal measure, as combining game and simulation, without the learning aspect, will only result in simulation games that are purely for entertainment (Akhtar et al., 2020).

Serious games can offer an interactive way to learn about a wide range of social issues, however, as Sharma (2020) expresses, it is not enough to simply produce a game focusing on a generalized social issue, it is necessary for developers to invest in principles of appropriate game design such as user experience, focus on immersive elements and interface improvement. Additionally, developers should conduct in-depth research on the subject itself so that there are no missed opportunities or misinformation conveyed through the game. Strong narrative design and storyline can induce a persuasive response from players, with the possibility of being further strengthened by level design elements that reflect the traditional architecture and building styles of a particular country or culture (Sharma, 2020).

There are important aspects that game designers must consider when projecting a serious game, such as the context in which is going to be used, their purposes, and their audience. Although the researchers Braad et al. (2016) stated that the wide range of purposes and target audiences addressed by serious games makes it complicated to discuss their design in general, they sustain that the serious games design requirements, like gameplay and technology, need to be in accordance with the future players. So in order to try to bridge the gap between the designer and the player, it is essential to involve members of the target audience in the design process, and to do so the authors proposed the integration of user information through research and user-centered design methods, which includes the player in the process either passively, such as participating in focus groups, testing and giving feedback, or actively, which can be considered participatory design.

Khaled and Vasalou (2014) explain that involving users as serious game co-designers can be complicated, because people who contribute to the design must master the content, the game mechanics, and the overall game design process. Although user participation has often been limited to providing feedback, inspirational input, and ideas that designers have developed, which indicates that users should be involved as informants rather than codesigners, participatory design for serious games can present opportunities for both the designers and the players, who can strengthen their domain knowledge as a result of actively contributing to the design process (Khaled and Vasalou, 2014).

Despite the variety of definitions and terminology related to serious games, Hawthorn et al (2021) believe that the way it is used is more important than the game's labeling, as seriousness can come from the context in which it is played, not necessarily from the genre, the designated purpose, or the nature of the game itself. It is often associated with the creator, designer, or facilitator of the game. Serious games have proven effective in promoting citizen engagement and social interaction, but for meaningful social interaction, game designers must consider players' preferences, needs, and requirements, while also paying attention to playful behavior with the environment and with other people around them (Fonseca et al., 2021).

\subsection{Social Innovation}

Social changes are not easily introduced. Even in 1970, Taylor (1970), after working for a few years in the field of interdisciplinary research, came across some issues he found challenging. Among them was the use of research in the community, and how change can be introduced and sustained, taking into account the challenges posed by interdisciplinary cooperation. According to the researcher, innovation is a sociological and psychological phenomenon, therefore, it is important to analyze how social inventions can be adapted, regardless of their presumed scientific merit. Applied social research must generate better forms of action, new ways of doing things and new social inventions, which should be tested and commercialized (Taylor, 1970).

The existence, process, and beneficial outcomes of social innovation have been documented by scholars for many years, with both academic and public interest. However, despite not being a new concept, having its sociological roots dating back to the end of the 19th century, it was little used until the 21 st century (Gentil et al., 2019). Research in this area has been criticized for being fragmented and non-cumulative, as the initial studies on the subject were carried out sporadically, in a non-cumulative way and with its conceptualization with a plurality of definitions. With this in mind, Van Der Have \& Rubalcaba (2016) conducted bibliometric analysis on the topic's research and concluded that the field of social innovation is based on four distinct intellectual communities that emerge through an organized diffusion process: community psychology, creativity research, social challenges and local development. Its main features can be seen in Table 2. 
Table 2. Organizational structure of research in Social Innovation (SI).

\begin{tabular}{|c|c|c|c|}
\hline $\begin{array}{l}\text { SI's intellectual } \\
\text { communities }\end{array}$ & SI's Basic View & Main key themes & Main results \\
\hline Community psychology & $\begin{array}{l}\text { Systematic strategies or } \\
\text { models for introducing } \\
\text { changes in social systems }\end{array}$ & $\begin{array}{c}\text { Management of ecological and } \\
\text { natural resources, among } \\
\text { others }\end{array}$ & $\begin{array}{l}\text { Changes in social and } \\
\text { behavioral systems }\end{array}$ \\
\hline Creativity Search & $\begin{array}{l}\text { SI generates creative process; } \\
\text { new ideas about social } \\
\text { organization to meet a } \\
\text { common goal }\end{array}$ & $\begin{array}{l}\text { Entrepreneurship, corporate } \\
\text { social responsibility, among } \\
\text { others }\end{array}$ & $\begin{array}{l}\text { New social relationships or } \\
\text { change in social organization }\end{array}$ \\
\hline Social challenges & $\begin{array}{l}\text { Innovative solutions for } \\
\text { socio-technical challenges or } \\
\text { social problems }\end{array}$ & $\begin{array}{l}\text { Sustainability, environment, } \\
\text { and health; cross-sector } \\
\text { alliances; social } \\
\text { entrepreneurship }\end{array}$ & $\begin{array}{c}\text { Socio-technical regime } \\
\text { transitions; Specific solutions }\end{array}$ \\
\hline Local development & $\begin{array}{l}\text { Meeting human needs } \\
\text { through a change in relations } \\
\text { between local civil } \\
\text { communities and their } \\
\text { government bodies }\end{array}$ & $\begin{array}{l}\text { Governance and institutions; } \\
\text { inclusion and empowerment } \\
\text { of citizens; urban and regional } \\
\text { issues }\end{array}$ & Social cohesion and change \\
\hline
\end{tabular}

Source: Own elaboration based on Van Der Have \& Rubalcaba (2016).

Social innovation is considered a multilevel phenomenon and, therefore, each of the intellectual communities identified by these authors could be explored by researchers in innovation studies, however, it is possible to conclude that they share two central conceptual elements: 1) changes in social relations, systems, or structures; and 2) the fact that such changes meet a shared human need or goal or solve a socially relevant problem. Therefore, any attempt to create a comprehensive definition for the field must be based on these two common components (Van Der Have \& Rubalcaba, 2016).

Pue et al. (2016) characterized social innovation as a process that encompasses the emergence and adoption of socially creative strategies that reconfigure social relationships to achieve a given social objective. For this to happen, one or more social entrepreneurs must devise a creative strategy to put into practice an idea that reconfigures society's approach to a given social problem. The authors define social entrepreneur as the prime mover in the social innovation process, who develops a socially creative strategy to solve a social problem. The researchers in question also claim that there can be socially entrepreneurial individuals and organizations, whose role in the process of social innovation can relate to three concepts: motivation, which may include social or personal factors such as self-expression, contribution to others, praise, or status; values, which are standards defined by culture that serves as a behavioral guide that influences attitudes, norms and beliefs, and by which people judge desirability and goodness; and individual faculties of the actor, that regards the capabilities and characteristics of the social entrepreneurs, in terms of personality traits, skills, as well as their socioeconomic status or organizational affiliation (Pue et al., 2016).

Social innovation is a way to mitigate social problems, resulting in new or improved solutions for a specific community, but, in addition, they understand the relations between different actors, institutions and the social context where the initiatives are inserted, showing themselves as an essential process for the evolution of society and the search for sustainable alternatives for collective well-being (Agostini et al., 2017).

A new paradigm of social innovation can be defined as a new and innovative solution that can be incorporated into products, processes, and services in order to meet social, economic and technological needs and to improve people's quality and quantity of life (Jali et al., 2017). It seeks to promote social transformation, participation, and inclusion of the less fortunate in society through empowerment, as the more widespread and promoted the social innovations, the greater development and social equity there will be for the country that receives them (Cordeiro, 2019).

In general, what can be identified as common in the researchers' conceptualization is that social innovation is a creative and differentiated response to a social situation considered unsatisfactory. Gentil et al. (2019) exemplified that social innovation results from cooperation between different actors, in a collective process of learning and knowledge creation, as well as the possibility of being organizational. It is possible to manifest itself 
in something tangible, such as a technology, a service or a product to generate action or intervention with the objective of modifying social relations, promoting social inclusion and cohesion (Gentil et al., 2019). Based on this information, one can start to think about the possibility of using serious games as a technology, product or service that can generate impacts of social innovation.

\section{Serious games that address social issues}

To better investigate the characteristics and trends in the area of serious games and to verify if the concepts and goals of social innovation can be identified in real serious games, four examples of games created with the purpose of solving or alleviating social problems are presented below, pointing out its main characteristics, creators and objectives. As a selection criterion, it was sought to present cases of analogue and digital games, created in different countries, found in journals and specialized websites. To find them, search combinations with keywords such as "serious game", "social innovation", "social change", "board game" and "digital game" were used.

\subsection{Good Shrimp Farming: responsible shrimp farming (Vietnam)}

Shrimp farming in Vietnam's Mekong Delta contributes to regional socioeconomic development but tends to have a negative environmental impact as it reduces mangrove area, increases shrimp disease, and marginalizes small owners. To try to influence the opinion, knowledge, and behavior of shrimp farmers in the region, Bosma et al. (2020) developed a serious board game called Good Shrimp Farming (Figure 1), which simulates the four main shrimp farming systems in the delta, presenting the risks and advantages of each. The game was expected to change the perception of shrimp farmers about the risk of disease outbreaks in shrimp and the importance of mangroves.

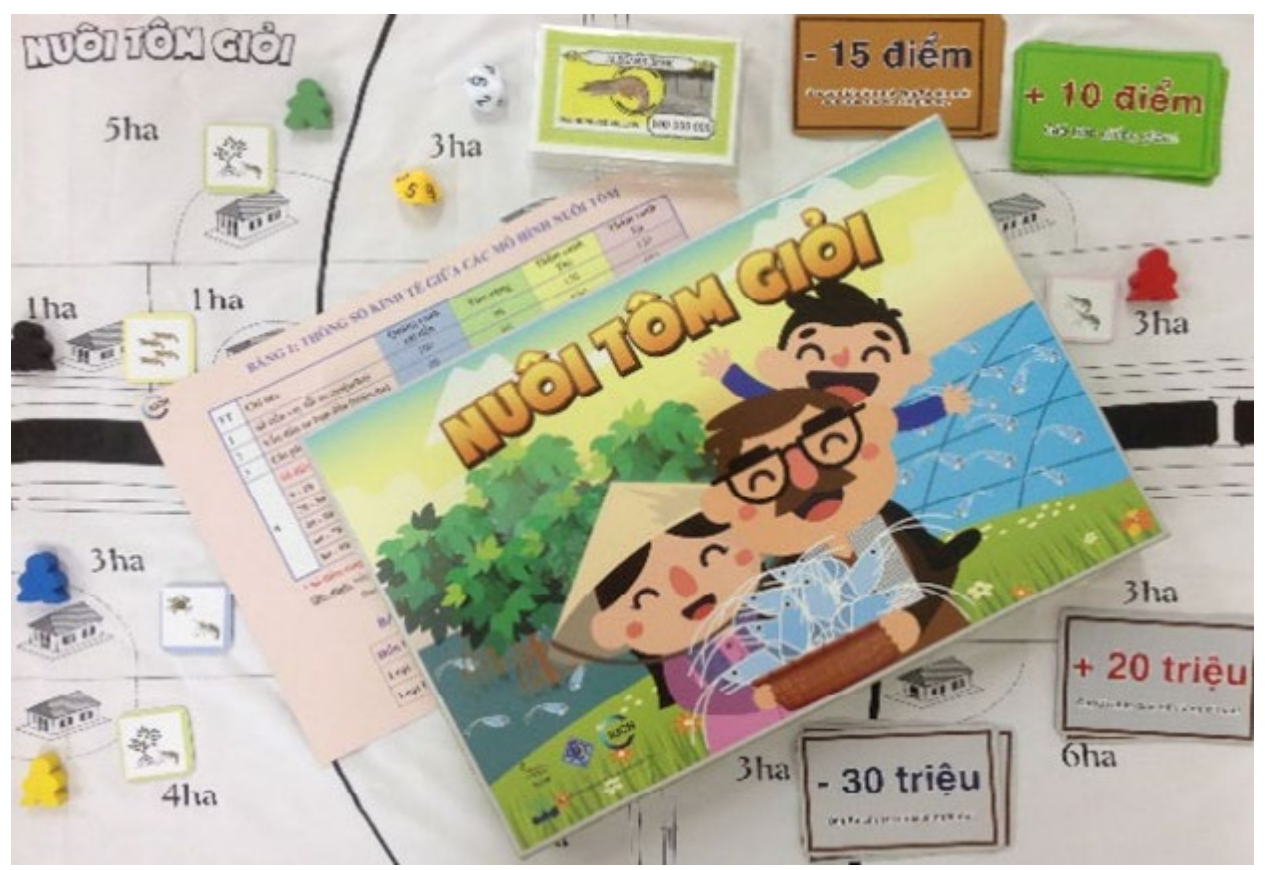

Figure 1. Good Shrimp Farming Game. Source: ALEGAMS Policy Brief, (Alegam, 2018).

After different matches of the game with shrimp breeders, the researchers evaluated how the gameplay influenced the players by collecting data during and after the plays. Shrimp farmers reported having learned about the risks of the intensive shrimp monoculture system and the advantages of using hybrid systems, because they impact only half of the mangroves. Evaluations showed that players adopted innovations more quickly and intensified better practices of doing their jobs. The researchers therefore concluded that serious board games have the ability to create social learning opportunities and reach out to groups that are not always easy to reach, as they enabled the transfer of knowledge and skills to shrimp farmers and developed their critical thinking (Bosma et al., 2020). 


\subsection{Orbit Rescue: child sexual abuse prevention (Australia)}

Orbit Rescue (Figure 2) is a serious game for computers and smartphones that is part of the Orbit child sexual abuse prevention program, created by the Engage Research Laboratory, at the University of the Sunshine Coast (USC), in Australia. With a spatial theme, the game aims to provide, in a practical way, important information about child sexual abuse to children aged 8 to 10 years, such as what to do in case of abuse and strategies to avoid it through the recognition of behavior predatory, using a positive and practical evidence-based approach and teaching safety practices. The program is partnered with the Queensland Police Service's Child Protection Unit, whose information provided realism and relevance to the gaming experiences. The game seeks to encourage children to develop relationships, trust, well-being, self-worth, esteem, and security (Rescue, 2021).

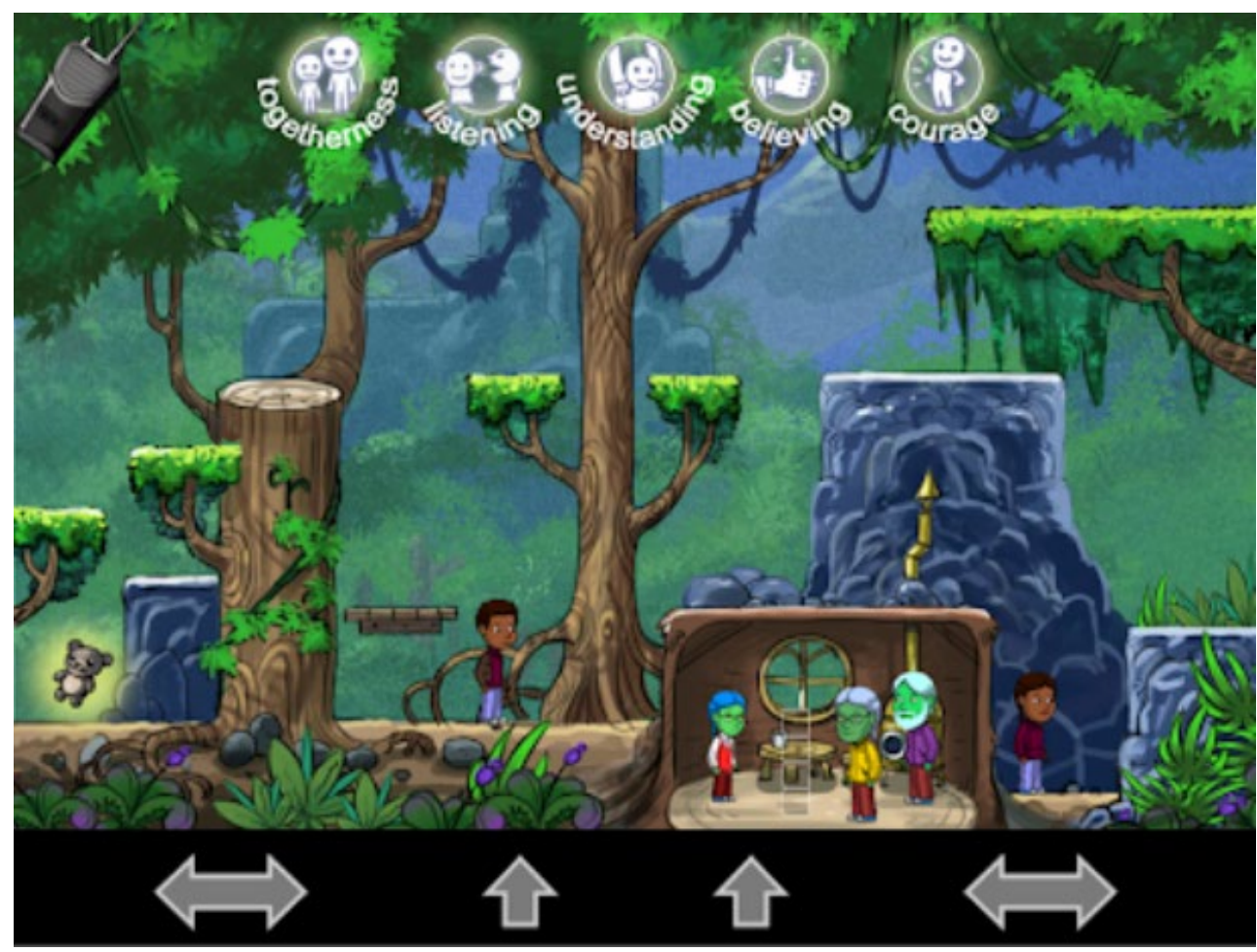

Figure 2. Orbit Rescue Game. Source: Rescue (2021).

A study on the game conducted by Jones et al. (2020) evaluated 139 children from a primary school in Queensland, who were divided into groups of students who played or not played Orbit Rescuet. Using the Australian questionnaire on child sexual abuse knowledge called CKAQ-R-III, applied before and after the game, it was found that children who played the game significantly increased their scores, while those who did not play had no improvement in punctuation. According to the researchers, the study showed the power of a serious games approach to teaching about child sexual abuse prevention in schools and how they can impact student learning.

\subsection{Bow River Sim: limited water resources management (Canada)}

In 2017, the Alberta Environment and Parks (AEP), the department responsible for the environment and the parks of the province of Alberta, Canada, developed a serious digital game called Bow River Sim (Figure 3) with the aim of helping the user to understand the water resources management model deployed by the department and to visualize the implications, impacts and social processes that occur when water in a basin is a scarce resource. The game simulates decision making for water management in the Bow River Basin, based on maximizing social, economic, and environmental benefits while managing limited water supply. It presents a way to improve the participants' engagement and learning in a water management planning process, presenting a powerful real water resources allocation model, incorporating gameplay and visual feedback. The game can be used by a variety of people, such as professionals, students, water-related decision makers, and dam operators (Akhtar et al., 2020). 


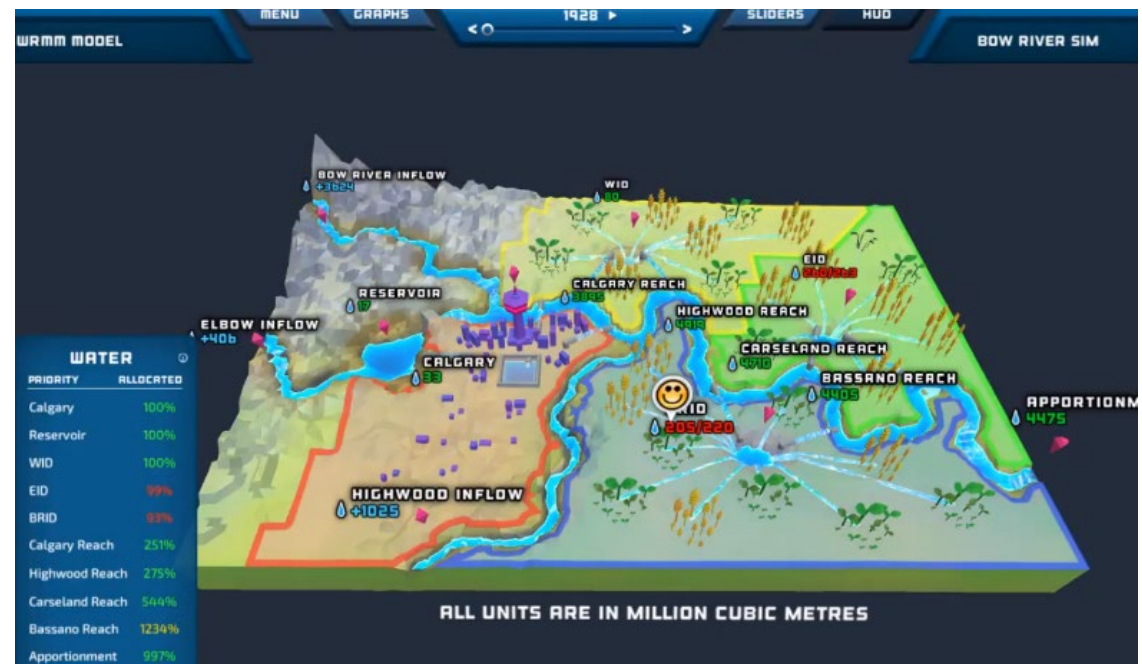

Figure 3. Bow River Sim game. Source: Alberta Environment (2018).

\subsection{Rise Up: fight for social justice (United States)}

Created by the organization Tesa Collective, from Massachusetts, in the United States, Rise Up (Figure 4) is a board game whose objective is to develop critical thinking in its players, building strategies and tactical skills to improve the social justice movement in the real world. In this game, all participants are on the same team and embark on a collaborative journey to stimulate the social movement and fight systemic problems, outlining creative strategies on the actions that each movement intends to achieve, such as, for example, creating viral videos, leading marches, and building alliances. According to its creators, the game has the potential to inspire social change to make the world better and teach tactical skills to achieve this goal. Rise Up features a doublesided board with two different games: a strategy game for experienced players and a game with simpler rules, with educational settings, for younger players.

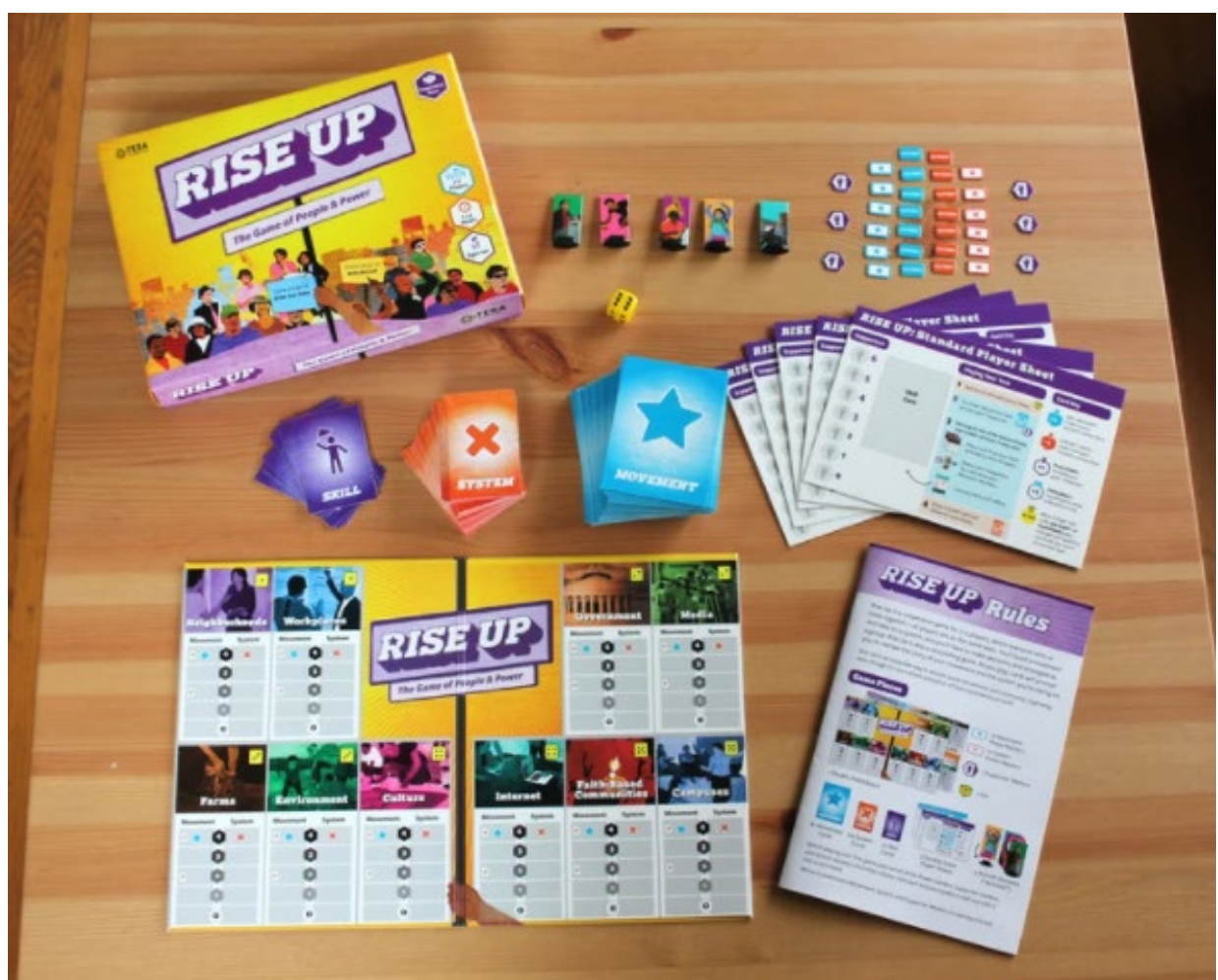

Figure 4. Rise Up. Source Tesa Collective (2017). 


\section{Results and discussion}

This article presented a literature review based on research and literary works on serious games and social innovation. In the first moment of the theoretical framework, it was presented how games have been used for different purposes in society, starting from something innate to man until its function of addressing more complex issues in society through teaching and learning, immersion, persuasiveness, stimulation cooperation and the ability to generate a sense of belonging (Huizinga, 2014; Johnson, 2016; Ampatzidou et al., 2018; Rocha, 2018; Medeiros, 2019; Klabbers, 2018). Then, the most recent studies on serious games were discussed, which are digital or analog games used within a well-defined space and that have a specific purpose that goes beyond entertainment, serving as a tool for the areas of education, training, health, well-being, advertising and communication and various fields of non-formal education (Olejniczak et al., 2020; Stewart et al., 2013; Mayer et al., 2016, Drummond et al., 2017; Wilkinson, 2016; Schrier, 2016; Akhtar et al., 2020; Sharma, 2020; Fonseca et al., 2021; Hawthorn et al., 2021).

The second item in the theoretical framework of the article presented references around the theme of social innovation. Although this is not a new focus of study in academia, it was found that research on the subject is still fragmented. However, through the bibliometric analysis presented by Van Der Have \& Rubalcaba (2016) and the statements of the other authors, it was possible to observe that the common concepts around social innovation are those that refer to it as creative strategies, which can be incorporated in products, processes and services, which cause changes in social relations, systems and structures and which meet an objective or need of a certain group of people, presenting itself, therefore, as a way to mitigate social problems and as an essential factor for development and social equity and for collective well-being (Taylor, 1970; Gentil et al., 2019; Van Der Have \& Rubalcaba, 2016; Pue et al., 2016; Agostini et al., 2017; Cordeiro, 2019; Jali et al., 2017; Gentil et al., 2019).

By analyzing the studies around the two themes, it was possible to observe that the objectives of serious games and the concepts of social innovation have several correlations. Both deal with serious issues of social interest and are considered systematic and creative strategies to present solutions that meet human needs and introduce positive changes in social systems and behaviors, education, natural resource management, social responsibility, challenges involving health and medical care, in the media, inclusion and empowerment of citizens and other issues that may present problems of social relevance (Schrier, 2016; Wilkinson, 2016; Van Der Have \& Rubalcaba, 2016, Mayer et al., 2016 ).

Serious games seem to respond in part to the questions around social innovation made by Taylor (1970), who at that time was still questioning himself about ways to introduce and maintain changes in a community despite the challenges posed by interdisciplinary cooperation. The author mentions that applied social research must generate better forms of action and new social inventions, which should be tested and commercialized. This dynamic can be observed in the creation of serious games, which, as shown in the four examples cited in this article, are created through research, with the aim of implementing an innovation to solve social problems and are tested to assess their effectiveness.

As previously mentioned, Pue et al. (2016) believe that for social innovation to happen a social entrepreneur, or a group of them, must devise a creative strategy to put certain idea into practice. Although the authors stated that social entrepreneurs can be individuals, it can be pointed out that, in the case of the four serious games investigated, their developers were all part of a team, weather inserted in a group of researchers or an organization. The authors also claim that, in the process of social innovation, said social entrepreneurs may relate to three different concepts, and, although the motives of each individual game developers weren't portraited in the publications around the four games researched, it's possible to identify that most of the group's incentive relate to motivation (as in social factors and contribution to others), value, and also individual faculties connected to skills and organizational affiliation, thus creating another link between concepts of social innovation and serious games.

It is also possible to observe that the games mentioned can be directly related to the recurrent themes in social innovation, mentioned in this article through the organizational structure of the social innovation research elaborated by Van Der Have \& Rubalcaba (2016) and the concepts described by Agostini et al. (2017), Jali et al. (2017), Cordeiro (2019) and Gentil et al. (2019). This correlation was shown in Table 3. 
Table 3. Social innovation themes present in the serious games studied.

\begin{tabular}{ccccc}
\hline Recurring Themes in Social Innovation & $\begin{array}{c}\text { Good Shrimp } \\
\text { Farming }\end{array}$ & Orbit Rescue & Bow River Sim & Rise Up \\
\hline Ecological Resource Management & $\mathrm{X}$ & $\mathrm{X}$ & $\mathrm{X}$ \\
Changes in social and behavioral systems & $\mathrm{X}$ & $\mathrm{X}$ & $\mathrm{X}$ \\
Social responsibility & $\mathrm{X}$ & $\mathrm{X}$ & $\mathrm{X}$ & $\mathrm{X}$ \\
Solutions for socio-technical challenges & & $\mathrm{X}$ & $\mathrm{X}$ \\
Urban and regional issues & $\mathrm{X}$ & $\mathrm{X}$ & $\mathrm{X}$ \\
Inclusion and empowerment of citizens & $\mathrm{X}$ & $\mathrm{X}$ & $\mathrm{X}$ & \\
Meet human needs & $\mathrm{X}$ & $\mathrm{X}$ & $\mathrm{X}$ \\
Sustainable alternatives & $\mathrm{X}$ & $\mathrm{X}$ & $\mathrm{X}$ \\
Social entrepreneurship & $\mathrm{X}$ & $\mathrm{X}$ & \\
Economic needs & $\mathrm{X}$ & $\mathrm{X}$ & \\
Health issues & & & & \\
\hline
\end{tabular}

Source: Own elaboration.

All games presented exhibit features that align with both the concepts gathered around serious games and social innovation. The Good Shrimp Farming game featured ten of the twelve recurring themes in the social innovation study, while Bow River Sim presented nine, and Rise Up and Orbit Rescue featured six of them. All four games analyzed presented themes that involve social responsibility, the inclusion and empowerment of citizens, the solution of human needs and the promotion of change in the relationships between communities. It was also possible to observe that each game intended to reach different audiences, whether they are shrimp farmers, managers, adults, or children, which demonstrates the adaptability of serious games.

Overall, the research perpetrated in this paper was able to answer its main question, that asked weather serious games can be considered as social innovation tools and be used to achieve social innovation goals based on studies surrounding both subjects. The concepts and objectives of serious games and social innovation were shown to have many correlations, social innovation being a broader concept that encompasses different methods, and as assured by this article, serious games can be considered one of them. Therefore, it was concluded that serious games can indeed be considered as tools for social innovation.

\section{Final Considerations}

The theoretical framework gathered in this research and the analyses of the four games presented allowed us to see more clearly the possibility of serious games being considered a tool to achieve social innovation goals. Both serious games and social innovation are considered creative strategies, with the proposal to introduce positive changes in social systems and behaviors to meet human needs or desires around issues that may present problems of social relevance.

Serious games have proven to be creative products for tackling social problems, and social innovation, if properly encouraged and valued, also aims to bring solutions to urgent social issues that citizens face, but the latter is about a broader concept that encompasses different methods. Therefore, it is concluded that serious games can be considered as tools for social innovation. However, for the goals of social innovation to be achieved through serious games, it is necessary that these be developed based on significant research on the subject that is intended to be addressed, so that the most important and correct information is transmitted. Another possible limiting factor for this to happen is the development of a discouraging game with poorly planned gameplay. Therefore, design principles focused on the user experience and methods that involve the players input and participation should be prioritized, so that players can take full advantage of the game's dynamics and the opportunities it can offer and thus increasing the chances of achieving its purpose. 
The study of social innovation is still somewhat fragmented, which justifies the importance of further research on the subject. Also, no research was found that conducted a direct comparison between the two terms social innovation and serious games, as proposed in this work. It is hoped then that this article contributes to future studies and implementations about the areas addressed and serves as a basis for further research. An obstacle found during this research was the lack of more detailed information about the design process of the four researched serious games, which prevented a deeper analysis of the user's participation in the design. Thus, for future studies, we propose another research focusing on serious games design processes, analyzing different studies and cases in which games were developed with social innovation purposes.

Serious games may not be the solution to all of society's complex issues, but they are part of a growing market and present themselves as tools with great potential to transmit knowledge and change behavior, as, in addition to presenting pedagogical principles, they have a great motivational effect through of immersion, interactivity and user-centered approach. But they go beyond that, as the serious games dynamic has the ability to point out solutions and provide important data about the people who are participating. In general, they provoke reflection and convey a message of social impact, serving as an instrument for collective well-being.

\section{References}

Agostini, M. R., Vieira, L. M., Tondolo, R. R. P., \& Tondolo, V. A. G. (2017). Uma visão geral sobre a pesquisa em inovação social: guia para estudos futuros. Brazilian Business Review, 14(4), 385-402. http://dx.doi.org/10.15728/bbr.2017.14.4.2.

Akhtar, M. K., De La Chevrotière, C., Tanzeeba, S., Tang, T., \& Grover, P. (2020). A serious gaming tool: bow river sim for communicating integrated water resources management. Journal of Hydroinformatics, 22(3), 491-509. http://dx.doi.org/10.2166/hydro.2020.089.

Alberta Environment. (2018). Bow River Sim - a serious game for water management in the Bow River Basin. Retrieved in 2021, June 2, from https://www.youtube.com/watch?v=pSEhUNqSFVo

Alegam. (2018). Coastal zones need both mangrove and shrimp. Alegams policy brief.. Retrieved in 2021, June 2, from https://sss.ctu.edu.vn/images/upload/NCKH/xhh/ALEGAMS/Policy-Brief_EnglishFinaL-2.pdf

Allied Market Research. (2019). Global serious games market 2019. GlobeNewswire news room, 2019. Retrieved in 2021, June 2, from https://www.globenewswire.com/news-release/2019/08/07/1898404/0/en/Global-Serious-Games-Market-Expected-to-Exhibita-19-2-CAGR-by-2025.html

Ampatzidou, C., Gugerell, K., Constantinescu, T., Devisch, O., Jauschneg, M., \& Berger, M. (2018). All work and no play? Facilitating serious games and gamified applications in participatory urban planning and governance. Urban Planning, 3(1), 34-46. http://dx.doi.org/10.17645/up.v3i1.1261.

Andrade, A. G., Amorim, F. R., Reis, N. F. (2021). Prospective Scenarios for Social Innovation. Research, Society and Development, 10(5), e35810515111. https://doi.org/10.33448/rsd-v10i5.15111

Avelino, F., Wittmayer, J., Pel, B., Weaver, P., Dumitru, A., Haxeltine, A., Kemp, R., Jørgensen, M. S., Bauler, T., Ruijsink, S., \& O'riordan, T. (2019). Transformative social innovation and (dis)empowerment. Technological Forecasting and Social Change, 145 195-206. http://dx.doi.org/10.1016/j.techfore.2017.05.002

Bosma, R. H., Ha, T. T. P., Hiep, T. Q., Phuong, N. T. H., Ligtenberg, A., Rodela, R., \& Bregt, A. K. (2020). Changing opinion, knowledge, skill and behaviour of Vietnamese shrimp farmers by using serious board games. Journal of Agricultural Education and Extension, 26(2), 203-221. http://dx.doi.org/10.1080/1389224X.2019.1671205.

Braad, E., Žavcer, G., \& Sandovar, A. (2016). Processes and models for serious game design and development. In: R. Dörner, S. Göbel, M. Kickmeier-Rust, M. Masuch \& K. Zweig (Eds.), Entertainment computing and serious games. Lecture notes in computer science. (vol. 9970, pp. 92-118). Cham: Springer, https://doi.org/10.1007/978-3-319-46152-6_5

Cordeiro, K. L. (2019). Questões centrais do processo de inovação social no brasil. Gestão \& Conexões, 8(2), $105-117$. http://dx.doi.org/10.13071/regec.2317-5087.2019.8.2.22022.105-117.

Correia, S., Oliveira, V., Feitosa, M., \& Gómez, C. (2018). Inovação social para o desenvolvimento sustentável: um caminho possível. Administração Pública e Gestão Social, 10(3), 199-212. http://dx.doi.org/10.21118/apgs.v10i3.1441.

Drummond, D., Hadchouel, A., \& Tesnière, A. (2017). Serious games for health: three steps forwards. Advances in Simulation, 2(3), 1-8. http://dx.doi.org/10.1186/s41077-017-0036-3.

Fonseca, X., Slingerland, G., Lukosch, S., \& Brazie, F. (2021). Designing for meaningful social interaction in digital serious games. Entertainment Computing, 36, 100385. http://dx.doi.org/10.1016/j.entcom.2020.100385.

Gentil, P. P. C., Guimarães L. O., Pereira D. C., Diniz A. M., \& Ckagnazarof I. B. (2019). Governança territorial e inovação social nos processos de desenvolvimento regional em territórios de mineração: um modelo teórico em construção. Cadernos EBAPE.BR, 17(3), 5029-5522. http://dx.doi.org/10.1590/1679-395173778.

Hawthorn, S., Jesus, R.A., \& Baptista, M. (2021). A review of digital serious games for tsunami risk communication. International Journal of Serious Games, 8, 21-47.

Huizinga, J. (2014). Homo Ludens: o jogo como elemento da cultura. São Paulo: Editora Perspectiva.

Jali, M. N., Abas, Z., \& Ariffin, A. S. (2017). Social Innovation in the context of Strategic Knowledge Management Processes for Supply Chain Performance Enhancement. International Journal of Supply Chain Management, 6(1), 233-237.

Johnson, S. (2016). Wonderland: how play made the modern world. New York City: Pan Books. 
Jones, C., Scholes, L., Rolfe, B., \& Stieler-Hunt, C. (2020). A serious-game for child sexual abuse prevention: an evaluation of orbit. Child Abuse \& Neglect, 107, 104569. http://dx.doi.org/10.1016/j.chiabu.2020.104569.

Khaled, R., \& Vasalou, A. (2014). Bridging serious games and participatory design. International Journal of Child-Computer Interaction, 2(2), 93-100. http://dx.doi.org/10.1016/j.ijcci.2014.03.001.

Klabbers, J. H. (2018). On the architecture of game science. Simulation \& Gaming, 49(3), 207-245.

http://dx.doi.org/10.1177/1046878118762534.

Mayer, I., Warmelink, H., \& Zhou, Q. (2016). The utility of games for society Business and Politics. In: N. Rushby \& D. W. Surry (Eds.), The Wiley handbook of learning technology (pp. 406-435). Malden: John Wiley \& Sons.

http://dx.doi.org/10.1002/9781118736494.ch22.

Medeiros, D. P. (2019). Jogos analógicos como ferramentas estratégicas para as marcas. Design e Tecnologia, 9(17), 56-63. https://doi.org/10.23972/det2019iss17pp56-63

Olejniczak, K., Newcomer, K. E., \& Meijer, S. A. (2020). Advancing evaluation practice with serious games. The American Journal of Evaluation, 41(3), 339-366. http://dx.doi.org/10.1177/1098214020905897.

Rescue, O. (2021). The Orbit approach. Retrieved in 2021, June 2, from http://orbit.ht.dstier2.com/csa/the-orbit-approach/

Pue, K., Vandergeest, C., \& Breznitz, D. (2016). Toward a theory of social innovation. Innovation Policy Lab White Paper, 201601 .

Rocha, M. P. (2018). Explorando retórica de jogo no cruzamento entre jogos sérios e art games para aprendizagem: caso de estudo do projeto Beaconing [Dissertation]. Porto: Universidade do Porto.

Rosa, M., Almeida, M., \& González, M. (2019). Business games and creativity: a bibliometric study and research themes. Product: Management \& Development, 17(1), 31-32. http://dx.doi.org/10.4322/pmd.2019.002.

Schrier, K. S. (2016) Knowledge games: how playing games can solve problems, create insight, and make change. Baltimore: Johns Hopkins University Press.

Sharma, A. (2020). Persuasive/Serious Games: Agents of Change in Individual Beliefs [Dissertation]. Breda: Breda University. https://doi.org/10.13140/RG.2.2.10443.21281

Stewart, J., Bleumers, L., \& Van Looy, J. (2013). The Potential of Digital Games for Empowerment and Social Inclusion of Groups at Risk of Social and Economic Exclusion: Evidence and Opportunity for Policy. Seville: Joint Research Centre of the European Commission (JRC).

Taylor, J. B. (1970). Introducing social innovation. The Journal of Applied Behavioral Science, 6(1), 69-77.

Collective, T. (2017) Rise up: the game of people \& power. Retrieved in 2021, June 2, from https://store.tesacollective.com/products//rise-up/

Van Der Have, R. P., \& Rubalcaba, L. (2016). Social innovation research: an emerging area of innovation studies? Research Policy, 45(9), 1923-1935. http://dx.doi.org/10.1016/j.respol.2016.06.010.

Wilkinson, P. (2016) A brief history of serious games (pp. 17-41). Cham: Springer. 